This item was submitted to Loughborough's Research Repository by the author.

Items in Figshare are protected by copyright, with all rights reserved, unless otherwise indicated.

\title{
Reduction of secondary electron yield for E-cloud mitigation laser ablation surface engineering
}

\section{PLEASE CITE THE PUBLISHED VERSION}

https://doi.org/10.1016/j.apsusc.2017.02.013

\section{PUBLISHER}

(C) Elsevier B.V.

\section{VERSION}

AM (Accepted Manuscript)

\section{PUBLISHER STATEMENT}

This work is made available according to the conditions of the Creative Commons Attribution-NonCommercialNoDerivatives 4.0 International (CC BY-NC-ND 4.0) licence. Full details of this licence are available at: https://creativecommons.org/licenses/by-nc-nd/4.0/

\section{LICENCE}

CC BY-NC-ND 4.0

\section{REPOSITORY RECORD}

Valizadeh, Reza, O.B. Malyshev, S. Wang, T. Sian, Michael D. Cropper, and N. Sykes. 2019. "Reduction of Secondary Electron Yield for E-cloud Mitigation Laser Ablation Surface Engineering". figshare. https://hdl.handle.net/2134/24249. 


\title{
Reduction of Secondary Electron Yield for E-cloud Mitigation by Laser Ablation Surface Engineering
}

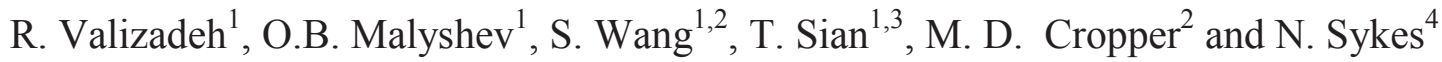 \\ ${ }^{1}$ ASTeC, STFC Daresbury Laboratory, Warrington WA4 4AD, UK \\ ${ }^{2}$ Department of Physics, Loughborough University, Loughborough LE11 3TU, UK \\ ${ }^{3}$ The Photon Science Institute, The University of Manchester, Manchester M13 9PL, UK \\ ${ }^{4}$ Micronanics Ltd., Didcot, Oxon OX11 0QX, UK
}

\begin{abstract}
Developing a surface with low Secondary Electron Yield (SEY) is one of the main ways of mitigating electron cloud and beam-induced electron multipacting in high-energy charged particle accelerators. In our previous publications, a low $\mathrm{SEY}<0.9$ for as-received metal surfaces modified by a nanosecond pulsed laser was reported. In this paper, the SEY of laser-treated blackened copper has been investigated as a function of different laser irradiation parameters. We explore and study the influence of micro- and nano-structures induced by laser surface treatment in air of copper samples as a function of various laser irradiation parameters such as peak power, laser wavelength $(\lambda=355 \mathrm{~nm}$ and $1064 \mathrm{~nm})$, number of pulses per point (scan speed and repetition rate) and fluence, on the SEY. The surface chemical composition was determined by x-ray photoelectron spectroscopy (XPS) which revealed that heating resulted in diffusion of oxygen into the bulk and induced the transformation of $\mathrm{CuO}$ to sub-stoichiometric oxide. The surface topography was examined with high resolution scanning electron microscopy (HRSEM) which showed that the laser-treated surfaces are dominated by microstructure grooves and nanostructure features.
\end{abstract}

\section{INTRODUCTION}

In high intensity particle accelerators with positively charged beams such as the LHC [1,2,3], KEKB [4], DAFNE [5], RHIC [6], PEP=II [7], etc., the beam induced electron multipacting (BIEM) and electron cloud (e-cloud) effects can significantly affect the quality of the beam and machine operation [8,9]. E-cloud was first observed on the proton/antiproton collider VAPP in the Budker Institute of Nuclear Physics in 1965 $[10,11]$. After more than 50 years since the first observation, the e-cloud remains a potential problem for many high intensity machines, thus the e-cloud has been studied for ILC [12] and is being investigated for the HL-LHC [13] and the FCC [14]. The initial electrons may appear due to synchrotron radiation producing 
photoelectrons or beam induced residual gas ionisation. These electrons can be accelerated up to several hundreds of $\mathrm{eV}$ in the electric field of the passing bunch. On colliding with the chamber wall, they will in turn produce further secondary electrons. This amplification leads to the build-up and dissipation of an electron cloud (e-cloud) along the beam path. E-cloud can affect the operation and performance of high energy charged particle accelerators in a variety of ways. It can induce increases in emittance, beam instability, vacuum pressure, beam losses, reduction in the beam lifetime, or additional heat loads on a (cryogenic) vacuum chamber. In RF wave guides, electron multipacting limits their lifetime and causes power loss, whereas in detectors the secondary electrons define the signal background and reduce the sensitivity.

It has been shown both theoretically and experimentally [3] that the e-cloud density build-up depends on the SEY function $\delta(E)$ and to minimize the effects of e-cloud, the $\delta_{\max }$ value should be less than a certain threshold value, but in most cases $\delta_{\max }<1$ would be a sufficient condition [3,15].

Since the secondary electron yield is influenced by the wall material, surface chemistry, topography and electron energy, any deliberate mitigation mechanism is based on engineering the first three of these parameters. There are a few ways of reducing the SEY:

(a) Choice of material with low SEY (for example, $\mathrm{Cu}$ has lower SEY than $\mathrm{Al}$ );

(b) Modifying surface geometry (e.g. making grooves) [3,16];

(c) Coating with low SEY materials (such as TiN [17], NEG [18] and amorphous carbon (a-C) [19]);

(d) Coating with low SEY microstructure (ex.: copper black, gold black; columnar NEG) [20,21,22];

(f) Various combinations of above.

Recently, a low $\mathrm{SEY}<0.9$ for as-received metal surfaces modified by a nanosecond pulsed laser was reported for the first time by Valizadeh et.al. [23,24]. Further development of this surfaces led to even lower value of $\mathrm{SEY}<0.6$ [25]. In comparison with other technologies for currently used surface engineering the laser treatment has a few advantages:

- The equipment is simpler;

- There is no need for vacuum or clean room facilities;

- Hierarchical structures containing both micro- and nanostructures can be created in a single laser treatment process; thus, the process is efficient;

- Surface modification is performed through a beam of light and thus contactless.

This work was focused on studying the influence of micro- and nano-structures induced by laser surface treatment in air of copper samples as function of various laser irradiation parameters such as peak power, laser, number of pulses per point (scan speed and repetition rate) and fluence, on the SEY. 


\section{EXPERIMENTAL}

\subsection{Sample preparation}

\subsubsection{Laser treated samples}

The samples were made of commercially available rolled, electro-polished oxygen-free copper $(\mathrm{Cu})$ with high purity of $99.999 \%$ and thickness of $1 \mathrm{~mm}, 50$ and $100 \mu \mathrm{m}$. Prior to laser exposure the samples were degreased. The samples were washed with acetone and then were irradiated by pulses of a Nd:YAG laser with different pulse durations operated at basic IR and third harmonic UV wavelength (1064 and $355 \mathrm{~nm}$ ) and various repetition rates ranging from 2.5 to $100 \mathrm{kHz}$. In all cases the laser beam had a Gaussian intensity profile and was focused on to the substrate surface using a flat-field scanning lens system. The diameter of the focused laser spot on each substrate between the points where the intensity has fallen to $1 / \mathrm{e}^{2}$ of the central value was set at $25 \mu \mathrm{m}$ for $\lambda=1064 \mathrm{~nm}$ and $15 \mu \mathrm{m}$ for $\lambda=355 \mathrm{~nm}$. The laser beam spot was scanned by galvanometric scanner across a $15 \mathrm{~mm} \times 15 \mathrm{~mm}$ sized area of the substrate. The pulse number reaching a given spot area was determined by varying the scanning speed, pulse repetition and the beam diameter. The laser fluence was varied between 2 and $154 \mathrm{~J} / \mathrm{cm}^{2}$. All the samples were irradiated in air at atmospheric pressure and at room temperature. Six sets of different laser parameters were used for this study shown in Table 1. The samples used in this study are summarised in Table 2.

Table 1: Different laser treatment parameters used for surface treatment.

\begin{tabular}{|c|c|c|c|c|c|c|c|c|c|}
\hline $\begin{array}{c}\text { Laser } \\
\text { treatment } \\
\text { condition }\end{array}$ & $\lambda(\mathrm{nm})$ & $\begin{array}{c}\text { Average } \\
\text { power } \\
(\mathrm{W})\end{array}$ & $\begin{array}{c}\text { Spot } \\
\text { size } \\
(\mu \mathrm{m})\end{array}$ & $\begin{array}{c}\text { Pulse } \\
\text { duration } \\
(\mathrm{ns})\end{array}$ & $\begin{array}{c}\text { Pulse } \\
\text { repetition } \\
(\mathrm{kHz})\end{array}$ & $\begin{array}{c}\text { Pitch } \\
\text { width } \\
(\mu \mathrm{m})\end{array}$ & $\begin{array}{c}\text { Scan } \\
\text { speed } \\
(\mathrm{mm} / \mathrm{s})\end{array}$ & $\begin{array}{c}\text { Energy } \\
\text { per } \\
\text { pulse } \\
(\mu \mathrm{J})\end{array}$ & $\begin{array}{c}\text { Fluence } \\
\left(\mathrm{J} / \mathrm{cm}^{2}\right)\end{array}$ \\
\hline 1 & 355 & 3 & 15 & 25 & 40 & 10 & $30,60,90$, & 75 & 42 \\
& & & & & & & & & \\
\hline 2 & 1064 & 1.9 & 25 & 70 & 2.5 & 20 & 125,180 & 760 & 154 \\
\hline 3 & 1064 & 2.4 & 25 & 70 & 5.0 & 20 & 125 & 480 & 97 \\
\hline 4 & 1064 & 3.6 & 25 & 70 & 10 & 20 & 30 & 360 & 73 \\
\hline 5 & 1064 & 3 & 25 & 70 & 20 & 10 & 500 & 150 & 30 \\
\hline 6 & 1064 & 1 & 25 & 70 & 100 & 10 & 500 & 10 & 2 \\
\hline
\end{tabular}

Table 2. List of samples.

\begin{tabular}{|c|c|c|c|c|}
\hline Sample no. & Thickness & Description & Condition & Parameters \\
\hline 1 & $1 \mathrm{~mm}$ & Cu reference sample & No treatment & - \\
\hline 2 & $1 \mathrm{~mm}$ & \multirow{5}{*}{$\begin{array}{c}\text { First laser system }(\lambda \\
=355 \mathrm{~nm})\end{array}$} & \multirow{5}{*}{$\begin{array}{c}\text { Condition 1, scan } \\
\text { speed varying }\end{array}$} & $180 \mathrm{~mm} / \mathrm{s}$ \\
\hline 3 & $1 \mathrm{~mm}$ & & & $120 \mathrm{~mm} / \mathrm{s}$ \\
\hline 4 & $1 \mathrm{~mm}$ & & & $90 \mathrm{~mm} / \mathrm{s}$ \\
\hline 5 & $1 \mathrm{~mm}$ & & & $60 \mathrm{~mm} / \mathrm{s}$ \\
\hline 6 & $1 \mathrm{~mm}$ & & & $30 \mathrm{~mm} / \mathrm{s}$ \\
\hline
\end{tabular}




\begin{tabular}{|c|c|c|c|c|}
\hline 7 & $100 \mu \mathrm{m}$ & \multirow{2}{*}{$\begin{array}{c}\text { Second laser system } \\
(\lambda=1064 \mathrm{~nm})\end{array}$} & Condition 2 & $2.5 \mathrm{kHz}$ \\
\cline { 5 - 5 } & $100 \mu \mathrm{m}$ & & Condition 3 & $5.0 \mathrm{kHz}$ \\
\cline { 5 - 5 } & $100 \mu \mathrm{m}$ & & Condition 4 & $10 \mathrm{kHz}$ \\
\hline $2^{*}$ & $1 \mathrm{~mm}$ & \multirow{2}{*}{$\begin{array}{c}\text { Second laser } \\
\text { treatments }\end{array}$} & Condition 5 and 6 & $500 \mathrm{~mm} / \mathrm{s}$ \\
\cline { 5 - 5 } $3^{*}$ & $1 \mathrm{~mm}$ & Condition 5 and 6 & $500 \mathrm{~mm} / \mathrm{s}$ \\
\hline 10 & $0.5 \mathrm{~mm}$ & Cu powder & No treatment & - \\
\hline 11 & $<10 \mu \mathrm{m}$ & & & - \\
\hline
\end{tabular}

\subsubsection{Powder samples}

The laser-treated surfaces have a microstructure and a nanostructure. In an attempt to explain the influence of laser treated surface on the SEY, copper powder was compacted on test samples. The powder was Goodfellow CU006024 and was stated to have a maximum particle size of $5 \mu \mathrm{m}$ and being spherical. Sample 10 was a $1 \mathrm{~mm}$ thick layer of $5 \mu \mathrm{m}$ copper powder on a stainless steel substrate. The powder was held in place using a $1 \mathrm{~mm}$ thick stainless steel wire that had been spot welded onto the sample holder shown in Fig. 1(a). Sample 11 was a thinner layer of the $\mathrm{Cu}$ powder. It was prepared by putting some of the powder into an acetone filled petri dish. The sample holder was then placed into the acetone and the petri dish was 'swirled' manually, a layer of powder was formed on the copper sample plate. This formed a thin layer of copper powder of few layers as shown in Fig. 1 (b), its thickness is estimated to be less than $10 \mu \mathrm{m}$.
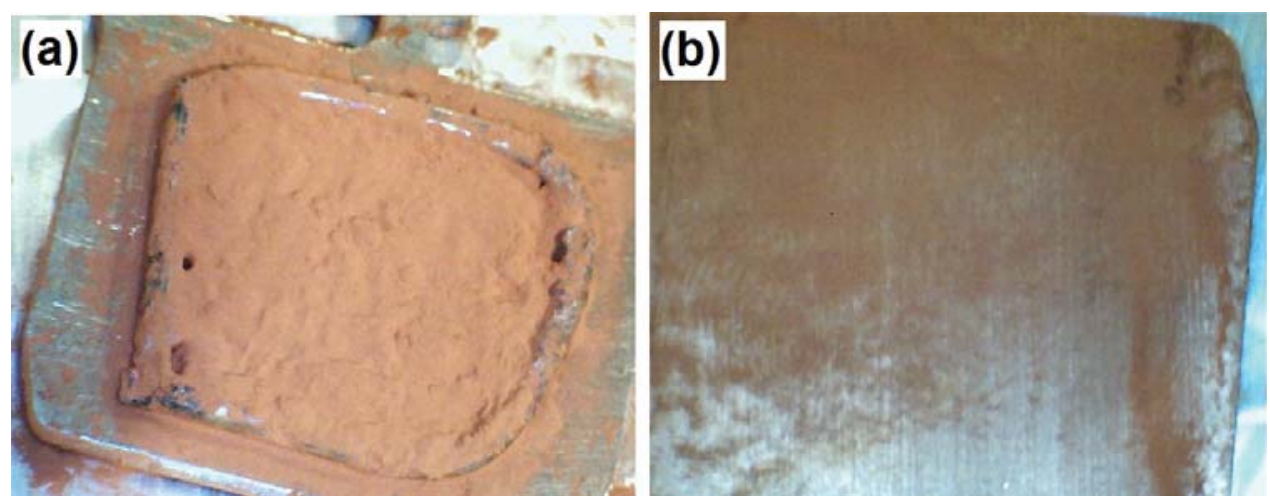

Figure 1: Images of 5 micron copper powder spread on standard Omicrons plates made of (a) Stainless Steel sample (Sample 10) and (b) copper (Sample 11).

\subsection{A facility for SEY studies}

A dedicated facility was designed, built and operated for SEY studies. The facility consists of three chambers as shown in Figure 2: a load-lock chamber, the SEY measurement chamber, the surface treatment and analysis chamber. After placing a sample into the load lock chamber, it was pumped there for at least 12 hours using a $210 \mathrm{l} / \mathrm{s}$ turbo-molecular pump (TMU 261, PFEIFFER Vacuum). The pressure of $2 \times 10^{-7} \mathrm{~Pa}$, measured using an MKS Pirani and inverted magnetron gauges, is routinely reached after overnight pumping from atmosphere. The sample is then transferred into the UHV SEY measurement chamber. The SEY measurement chamber is equipped with a combined NEG and sputter ion pump (NEXTORR® D100-5, 
SAES Getters), which enables a pressure of $2 \times 10^{-8} \mathrm{~Pa}$ without electron bombardment and of $(2-5) \times 10^{-7} \mathrm{~Pa}$ during electron bombardment. The pressure is measured using a Leybold extractor gauge.

The schematic layout of the SEY measurements is shown in Figure 1. The electron beam with energy ranging from 80 to $1000 \mathrm{eV}$ is generated by the Kimball electron gun (ELG-2/EGPS-2). The Faraday cup is made of 304L stainless steel and is an $85 \mathrm{~mm}$ long and $50 \mathrm{~mm}$ diameter cylinder with two plates on the top and bottom. The electrons enter the Faraday cup through the top 8-mm diameter hole passing through to the opposite site of the Faraday cup and bombard the sample placed in front of the 10-mm diameter hole on of the Faraday cup. The beam size at the sample (full width half maximum - FWHM) have been measured with a phosphor screen and wire scanner for different electron gun parameters and electron beam energies before performing the SEY experiments. The spot size during the SEY measurements was $0.28 \pm 0.04 \mathrm{~cm}^{2}$.

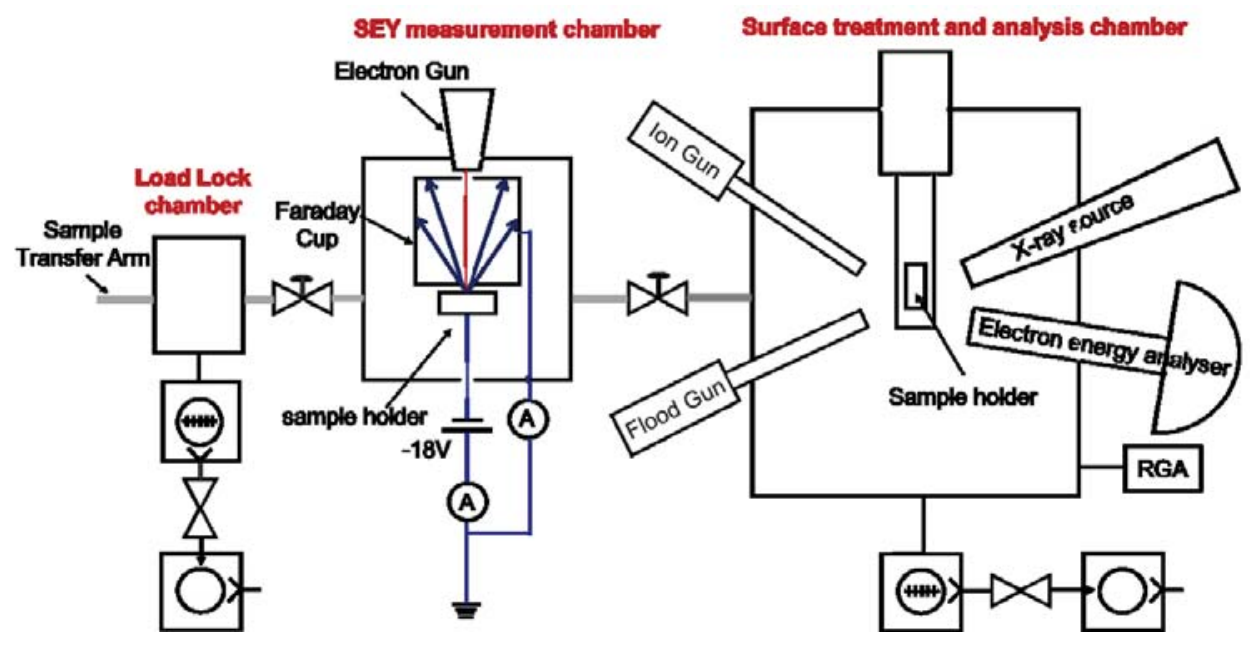

Figure 2: Schematic layout of the facility for SEY studies.

The secondary electrons are collected by the Faraday cup. The currents flowing through the sample and the Faraday cup are recorded for the SEY measurement.

The total SEY (or $\delta$ ) is defined as

$$
\delta=\frac{I_{F}}{I_{P}}=\frac{I_{F}}{I_{F}+I_{S}}
$$

where $I_{S}$ is the secondary electron current (including both elastic and inelastic processes) measured at the sample, $I_{F}$ is the current on the Faraday cup and $I_{P}$ is the primary beam current. In these experiments the net current at the sample biased at $-18 \mathrm{~V}$ and the Faraday cup at ground potential were measured with two current amplifiers (Keithley 6517A and Keithley 6485, accuracy $\pm 0.01 \%$ ). As the SEY is very sensitive to the electron dose, the total electron dose during the SEY measurements, as a function of primary energy, was not allowed to exceed $10^{-6} \mathrm{C} \cdot \mathrm{mm}^{-2}$. The accuracy of the SEY measurements was estimated with root mean square deviation procedure to be within $0.1 \%$ for primary electron energies between 80 and $1000 \mathrm{eV}$, 
however the repeatability of SEY for the same sample over different area of the sample lies within $\pm 2.5 \%$ which could be explained by small non-uniformity of the surface topography of studied samples.

After SEY measurements the sample can be transferred to the surface treatment and analysis chamber which is equipped with a flood gun ( $\mathrm{AG} 31 \mathrm{~F}, \mathrm{VG})$ used for electron conditioning (electron energy $485 \mathrm{eV}$ and the accuracy of the electron dose was within 10\%), an argon ion gun (PSP, ISIS 3000) with energy of $1.5 \mathrm{keV}$ for surface etching and a sample heater which allows sample heating up to $300{ }^{\circ} \mathrm{C}$. In addition the sample surface composition and chemical bonding energies can be analysed using an X-ray source and an electron energy analyser. XPS measurements are carried out using a hemispherical analyser fitted with a five channeltron detector. Power supplies are for the spectrometer a PSP Resolve Control and, for the detectors, a PSP \#705. The spectrometer was operated at $20 \mathrm{eV}$ pass energy at all times and the angle between the X-ray source and electron analyser is 70 degree. Photo-electrons are excited by nonmonochromatic Al Ka X-ray source $(h v=1463 \mathrm{eV})$ using VG twin anode, the Al anode used at all times operated at $10 \mathrm{keV}, 20 \mathrm{~mA}$.

The surface treatment and analysis chamber is equipped with a 340 1/s turbo-molecular pump (Leybold 340M) and 1000 1/s getter pump (CapaciTorr ${ }^{\circledR}$ D-1000 Pump, SAES Getters). The base pressure of about $10^{-7} \mathrm{~Pa}$ measured by a Leybold extractor gauge and the residual gas composition was monitored using a residual gas analyser (RGA, VG Thermo, VGQ).

The typical experimental procedure may involve SEY measurement of the as-received sample followed by XPS measurement, conditioning using the diffuse-beamed electrons from the flood gun, ion bombardment or thermal treatment, followed by another XPS measurement and another SEY measurement, etc.

\section{RESULTS:}

The surface topography of the samples 2-6 was examined using high resolution scanning electron microscopy (HRSEM, model JEOL 7001F FEG SEM). Treatment of copper using the first laser system $(\lambda=$ $355 \mathrm{~nm}$ ) resulted in creation of three different scales structures as presented in Fig. 3:

- microstructure grooves ranging from 8 to $100 \mu \mathrm{m}$ deep,

- coral-like submicron particles superimposed on the grooves which is made of agglomeration of

- nano-spheres. 

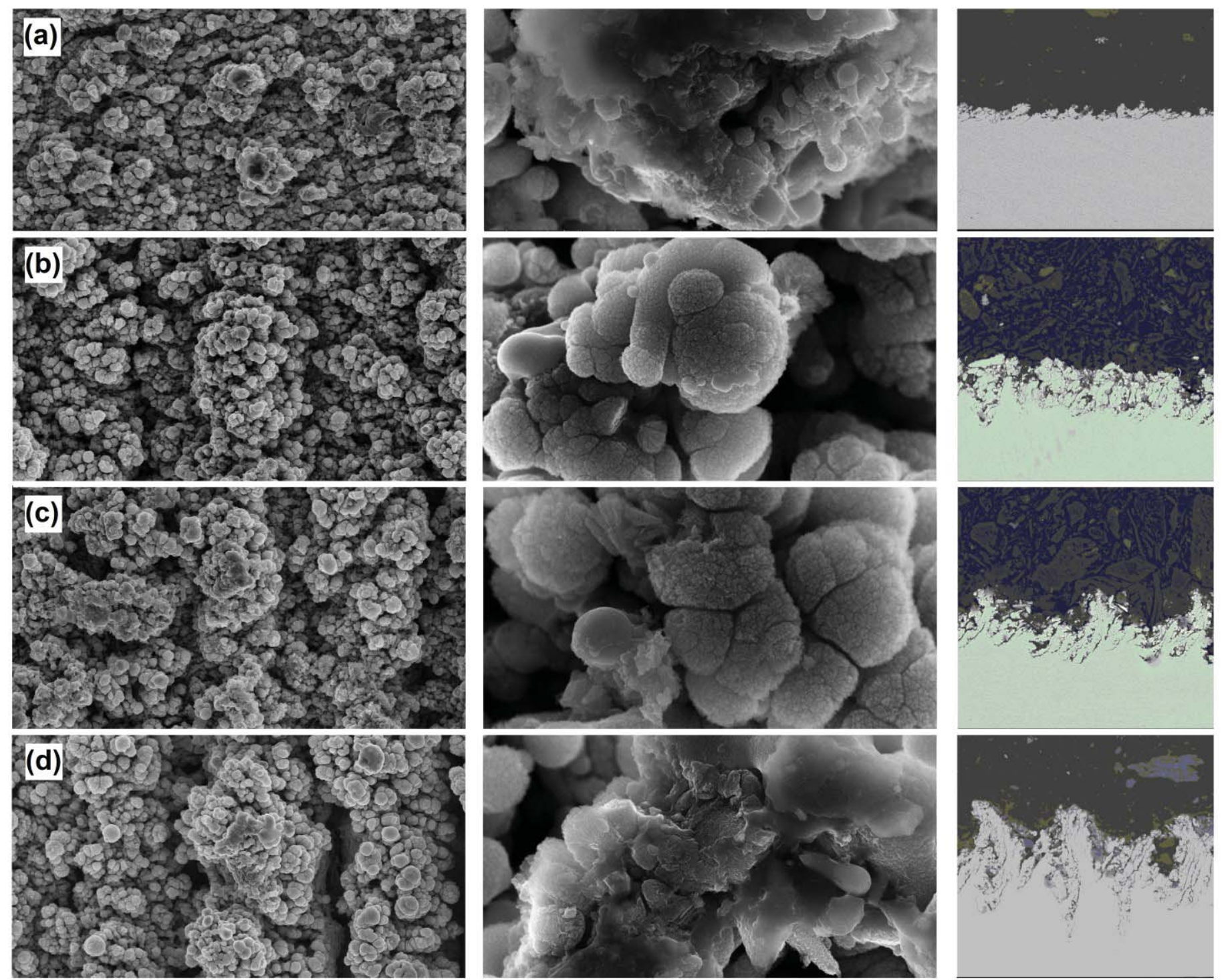

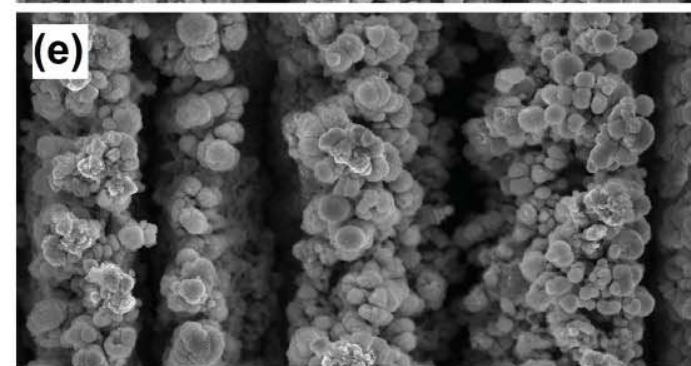

$\vdash 30 \mu \mathrm{m} \rightarrow$

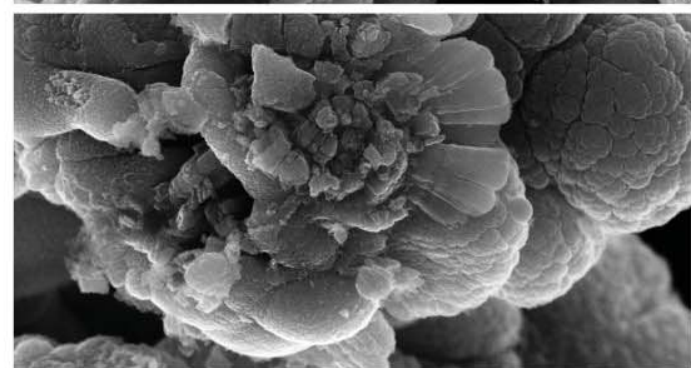

$\vdash 2 \mu \mathrm{m} \dashv$

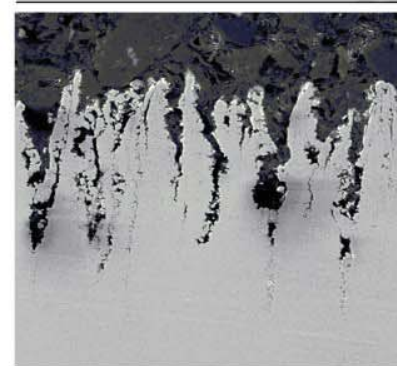

$\vdash 100 \mu \mathrm{m} \neg$

Figure 3: Low (on the left) and high (in the middle) resolution planar and X-Section (on the right) SEM micrographs of $1 \mathrm{~mm}$ thick copper samples 2-6 treated with laser using different scan speeds: (a) Sample 2, $180 \mathrm{~mm} / \mathrm{s}$, (b) Sample 3, $120 \mathrm{~mm} / \mathrm{s}$, (c) Sample 4, $90 \mathrm{~mm} / \mathrm{s}$, (d) Sample 5, $60 \mathrm{~mm} / \mathrm{s}$ and (e) Sample 6, $30 \mathrm{~mm} / \mathrm{s}$.

As can be seen from the cross-sectional SEM micrographs in Fig. 3 on the right, as the scan speed increases the depth of grooves decreases which should be expected since the number of shots per line decreases, however the superimposed submicron and nanostructures remain the same throughout the range of scan speeds (see Fig. 3) and more detail of the submicron and nanostructure is shown in a micrograph in Fig. 3 (middle), which is the same for these five samples. The depth of the groove and the SEY value at low and high primary electron energy for the respective scan speed are summarised in Table 3. 
Table 3: The depth of grooves and lowest and highest SEY in respect to scan speed.

\begin{tabular}{|l|l|l|l|l|l|}
\hline Sample & 6 & 5 & 4 & 3 & 2 \\
\hline Scan speed $(\mathrm{mm} / \mathrm{s})$ & 30 & 60 & 90 & 120 & 180 \\
\hline Groove depth $(\mu \mathrm{m})$ & 100 & 60 & 35 & 20 & 8 \\
\hline$\delta$ at $\mathrm{E}_{\mathrm{p}}=60 \mathrm{eV}$ & 0.6 & 0.5 & 0.3 & 0.3 & 0.4 \\
\hline$\delta$ at $\mathrm{E}_{\mathrm{p}}=1000 \mathrm{eV}$ & 1.0 & 0.91 & 0.91 & 0.98 & 1.22 \\
\hline
\end{tabular}

The SEY of Samples 2-6 is shown in Fig. 4 as a function of primary electron energy, $\delta\left(E_{\mathrm{p}}\right)$, for the five different scan speeds. These results were obtained after placing the samples in vacuum followed by ten hours of pumping without any treatment, described later as 'as-received samples'. It shows that besides the $180 \mathrm{~mm} / \mathrm{s}$ scan speed condition in all other cases for the as-received samples the SEY remained below 1. Typically, SEY as a function of primary energy follows the same trend as shown in Fig. 4 for the untreated $\mathrm{Cu}$ (Sample 1). The SEY is below 1 at low values of primary electron energy $(\sim 10 \mathrm{eV})$ and increases steadily to rise above 1 at an energy typically $\mathrm{E}_{1}=80 \mathrm{eV}$ and then reaches a maximum value $2<\delta_{\max }<3$ at an energy $\mathrm{E}_{\max }$ ranging between 200 to $300 \mathrm{eV}$. It then follows a steady decline to below 1 at higher $\mathrm{E}_{\mathrm{p}}$. In the case of the laser treated surface with the scan speed below $180 \mathrm{~mm} / \mathrm{s}$ the SEY values stays below 1 for the entire range of primary electron energy employed in this study. The SEY rises initially for primary electron energies below $200 \mathrm{eV}$. For energies $200 \mathrm{eV}<\mathrm{E}_{\mathrm{p}}<400 \mathrm{eV}$ the rate of increase reduces and flattens off with much lower gradient towards the higher primary electron energy.

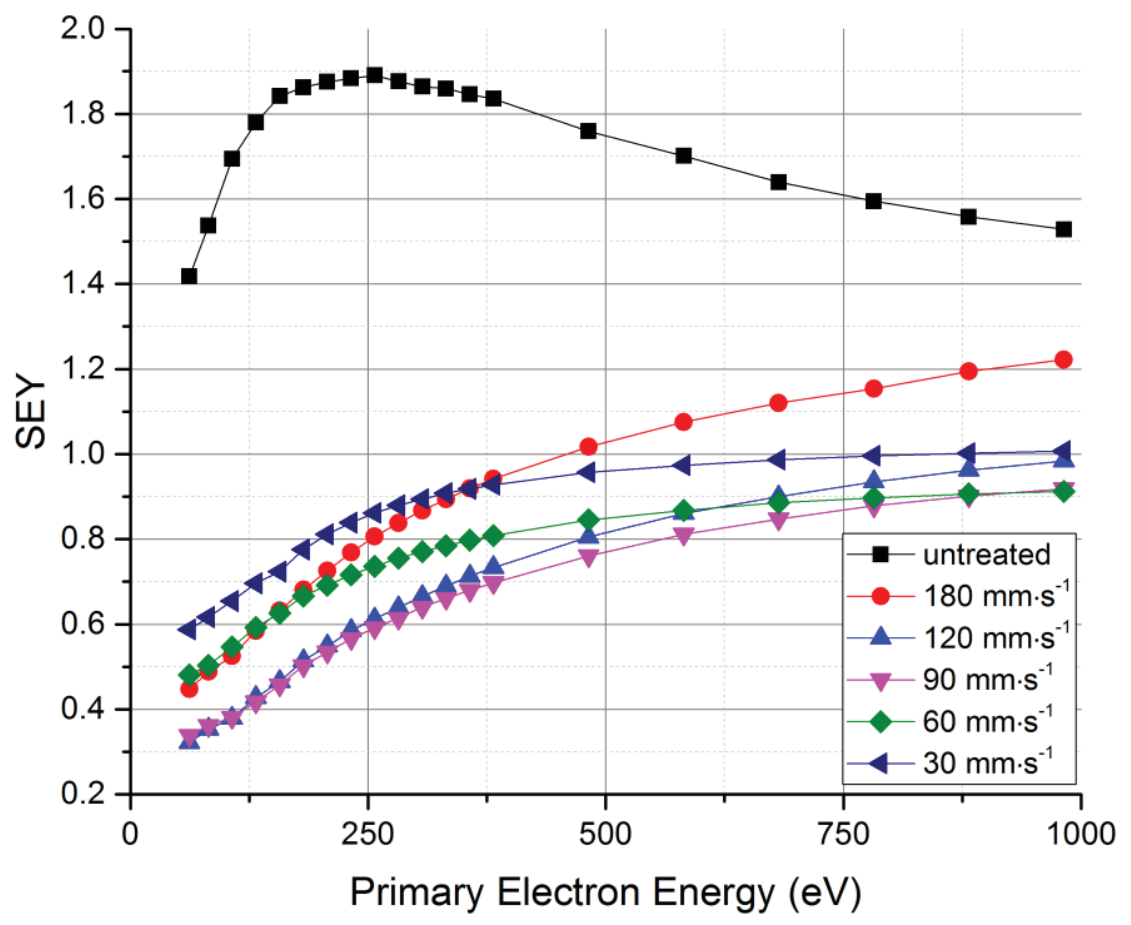

Figure 4: SEY of laser treated Samples 2-6 with varying scan speed as a function of primary electron energy and non-treated Sample 1.

The XPS Cu2p region spectra of $\mathrm{Cu}$ for the as-received sample $(30 \mathrm{~mm} / \mathrm{s})$ is shown in Fig. 5. It can be seen that the $\mathrm{Cu}$ at the surface is in $\mathrm{CuO}$ oxide state. This is evident (a) by the presence of the high intensity $\mathrm{Cu}^{2+}$ 
broad peak shake up satellites at about $9 \mathrm{eV}$ higher binding energy than the main $2 \mathrm{p}_{3 / 2}$ and $2 \mathrm{p}_{1 / 2}$ peaks at binding energy of 943 and $963 \mathrm{eV}$ and (b) from the distinctive x-ray exited Cu LMM Auger spectra at 917 eV kinetic energy shown as inset in Fig. 5. Also, in all cases no carbon peak was observed.

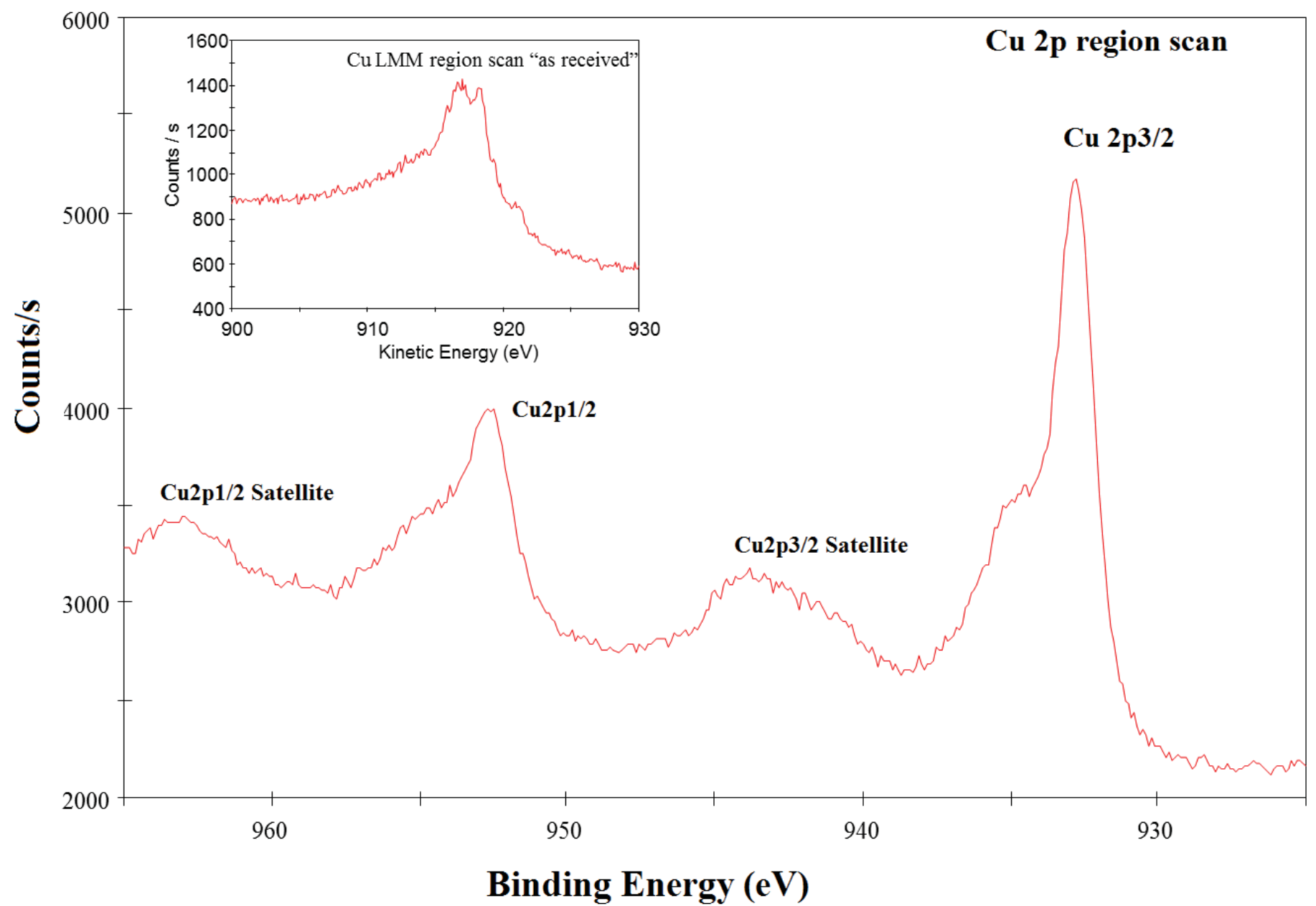

Figure 5: XPS spectra of $\mathrm{Cu} 2 \mathrm{p}$ region for the scan speed of $30 \mathrm{~mm} / \mathrm{s}$ used with $355 \mathrm{~nm}$ laser. The inset is the $\mathrm{X}-\mathrm{ray}$ exited $\mathrm{Cu}$ LMM Auger.

Figures 6 and 7 represent the planar view of copper surfaces of Samples 7 and 8 being treated with laser parameters 2 and 3 as stated in Table 1. Where Fig. 6 shows the low resolution image which is similar for both conditions and Fig. 7 shows the difference between them at higher resolution. In both cases the surface consists of a shallow microgrooves, sub-microstructures resembling volcanic sponges covered with nanosize wire/filament/fibre like structure. 

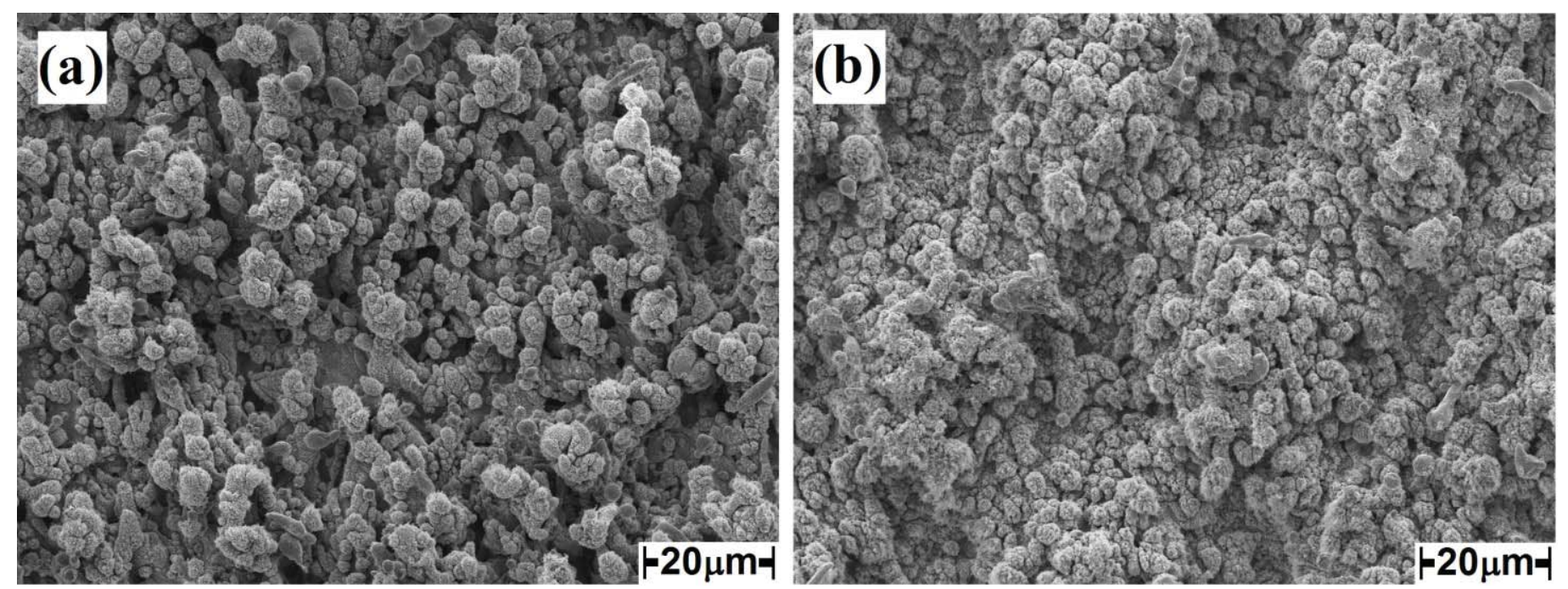

Figure 6: A low resolution image of surfaces of Samples 7 and 8 being treated with laser parameters 2 and 3.

The SEY as a function of primary electron energy, $\delta\left(E_{p}\right)$, for the copper Samples 7 and 8 is shown in Fig. 8. It can be seen that in comparison with non laser-irradiated samples, $\delta\left(E_{p}\right)$ increases as the primary electron energy increases, however $\delta\left(\mathrm{E}_{\mathrm{p}}\right)$ is considerably reduced at energy between $200 \mathrm{eV}<\mathrm{E}_{\mathrm{p}}<400 \mathrm{eV}$ which is the critical energy range for e-cloud build-up in a machine like the LHC. The observed trend is very simular to $\delta\left(E_{p}\right)$ trend of Samples 2 irradiated with $355 \mathrm{~nm}$ laser at higher scanning speed of $180 \mathrm{~mm} / \mathrm{s}$ but with higher values for all the primary electron energy. 

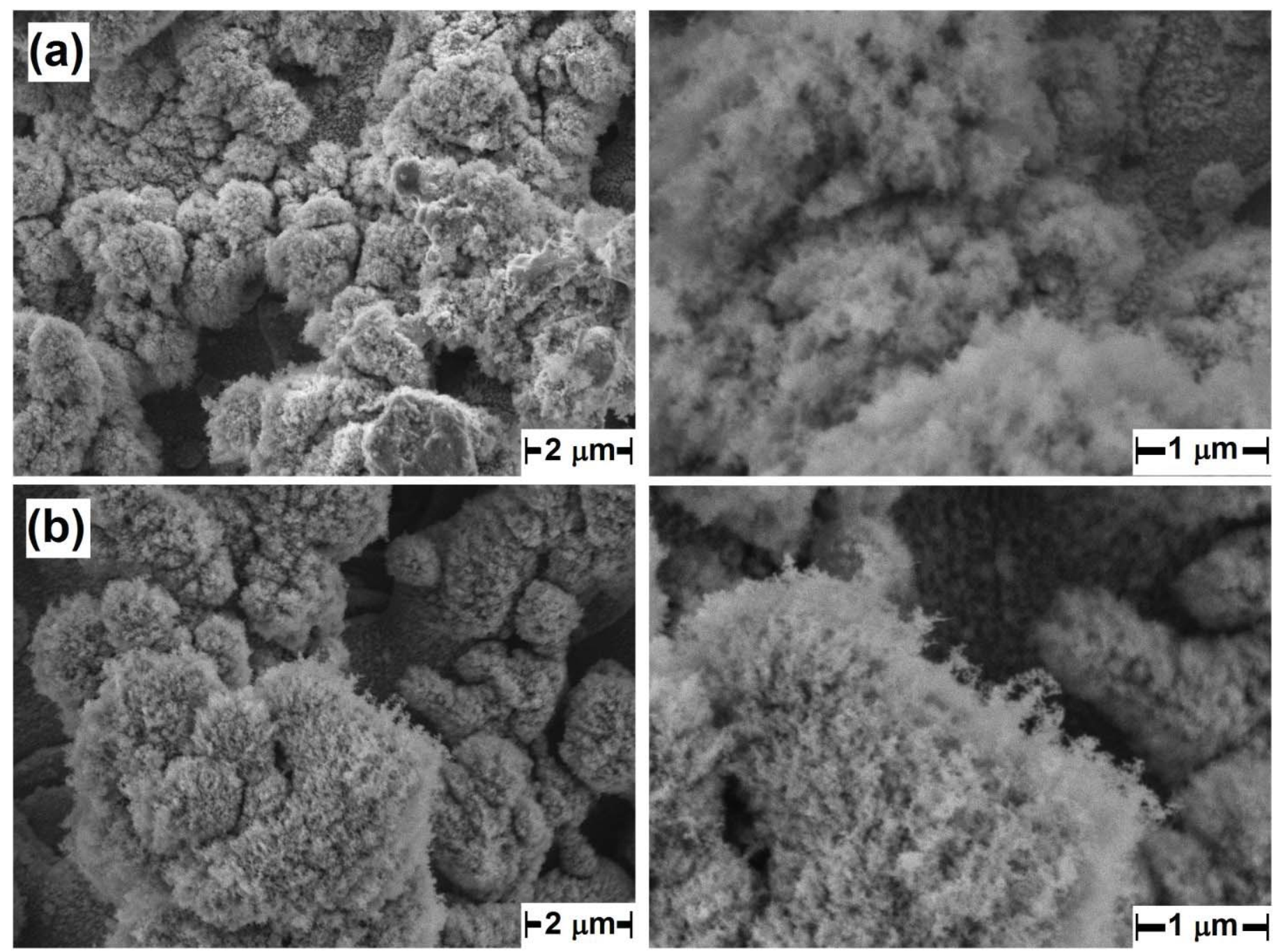

Figure 7: High resolution plan view SEM micrograph (two different resolutions with the highest on the right side) of copper irradiated with laser $\lambda=1064 \mathrm{~nm}$, scan speed of $125 \mathrm{~mm} / \mathrm{s}$, at (a) $2.5 \mathrm{kHz}$ repetition rate (Sample 7, condition 2), (b) $5 \mathrm{kHz}$ repetition rate (Sample 8, condition 3).

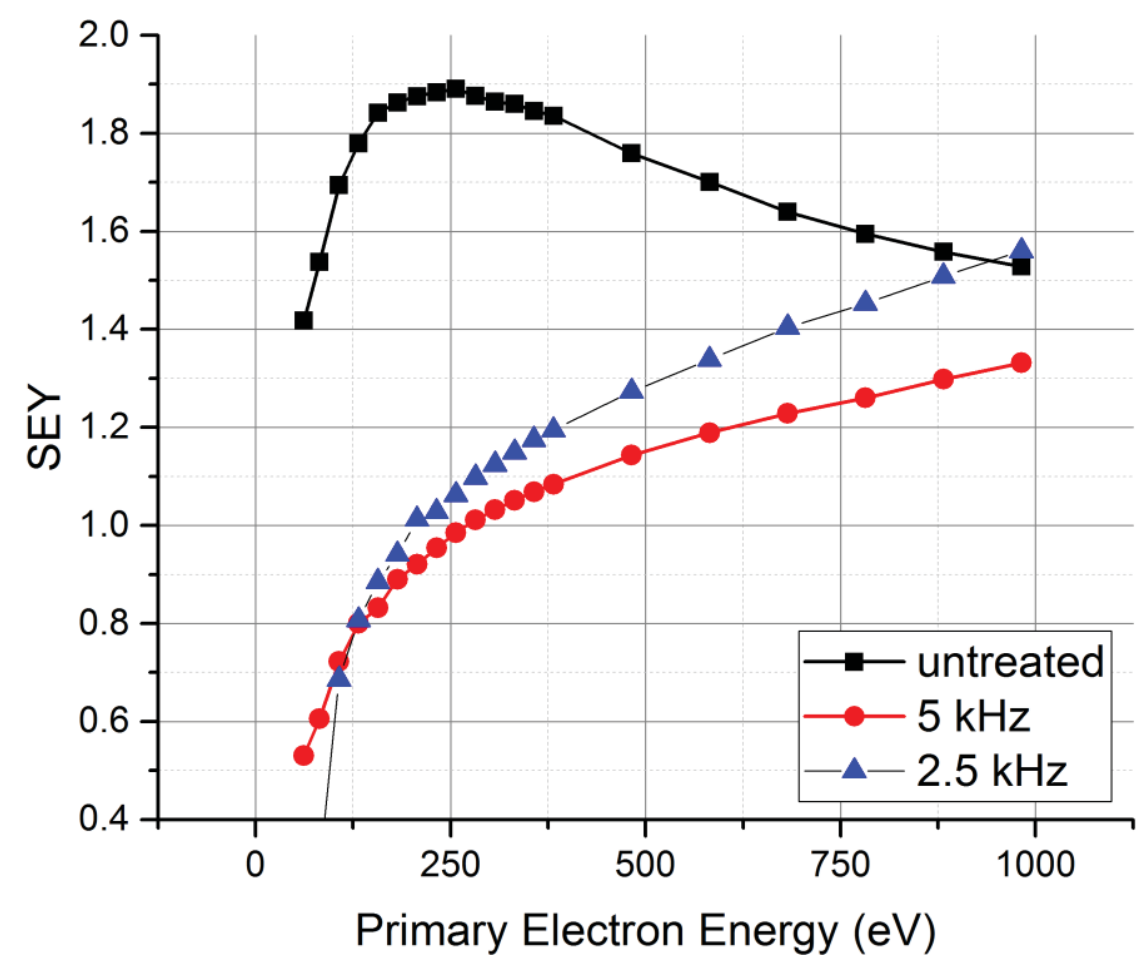


Figure 8: SEY of copper irradiated with laser $\lambda=1064 \mathrm{~nm}$, scan speed of $125 \mathrm{~mm} / \mathrm{s}$, at (a) $2.5 \mathrm{kHz}$ repetition rate (Condition 2, Sample 7), (b) $5 \mathrm{kHz}$ repetition rate (Condition 3, Sample 8).

Figure 9, represents the low and high resolution planar and cross-sectional SEM micrographs of $100 \mu \mathrm{m}$ thick copper surfaces of Sample 9 being treated with laser parameters 4 as stated in Table 1. The surface consists of a mixture of nano, submicron and microstructures observed for condition 1 and 3. It is covered by coral- like nano-porous spheres superimposed on microstructure grooves extending up to $60 \mu \mathrm{m}$ deep.
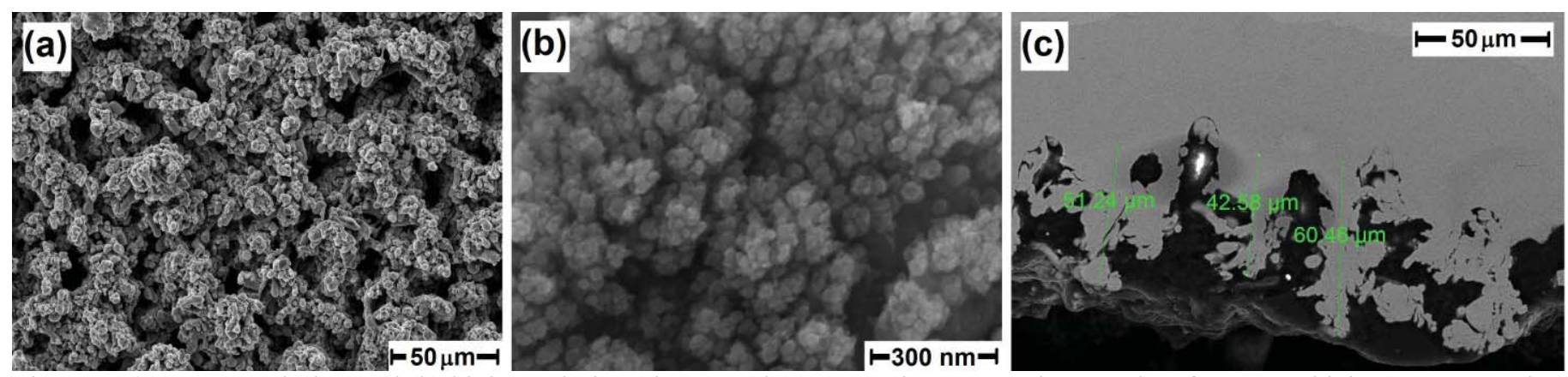

Figure 9: (a) Low resolution and (b) high resolution planar and (c) X-Section SEM micrographs of $100 \mu \mathrm{m}$ thick copper Sample 9 treated with $\lambda=1064$ laser at $10 \mathrm{kHz}$, scan speed of $30 \mathrm{~mm} / \mathrm{s}$ and pitch distance of $30 \mu \mathrm{m}$ (Condition 4).

The surface topography of Sample 9 induced by $\lambda=1064$ laser is comparable to the surface structure of the Sample 5 irradiated with $355 \mathrm{~nm}$ laser at a scan speed of $60 \mathrm{~mm} / \mathrm{s}$. The measured $\delta\left(\mathrm{E}_{\mathrm{p}}\right)$ is shown Fig. 10 and it can be seen that it matches closely both in terms of trend and value to the SEY obtained for the Samples 5 and 9. The SEY $(\delta)$ values are below 1 at all the primary electron energies of $60 \mathrm{eV}<\mathrm{E}_{\mathrm{p}}<1000 \mathrm{eV}$.

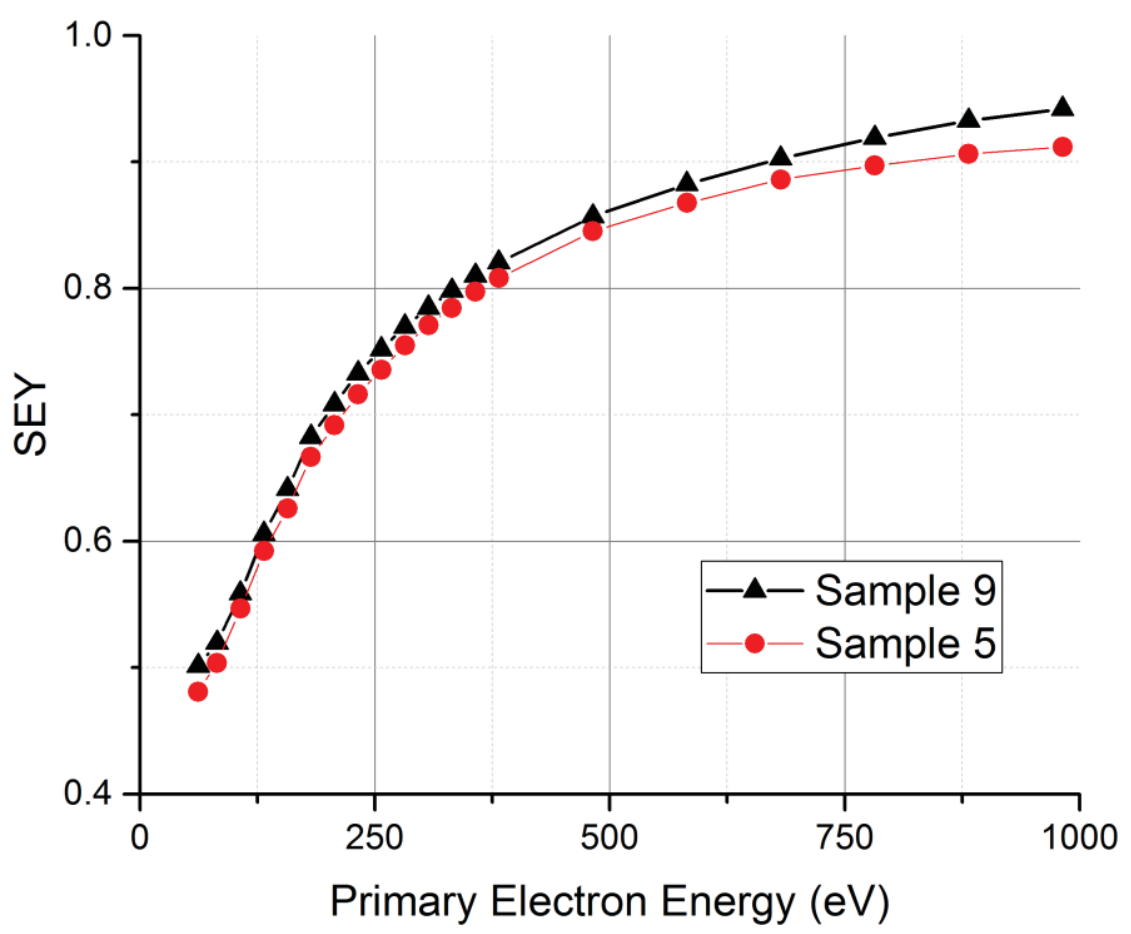

Figure 10: SEY as a function primary electron energy of $100 \mu \mathrm{m}$ thick copper Sample 9 treated with $\lambda=1064$ laser at $10 \mathrm{kHz}$, scan speed of $30 \mathrm{~mm} / \mathrm{s}$ and pitch distance of $30 \mu \mathrm{m}$ (Condition 4). 
Figure 11, represents the low and high resolution planar SEM micrograph of copper surfaces of Samples 2 and 3 after being irradiated for a second time with laser parameters 5 and 6 , named now as Samples $2 *$ and 3*. It can be seen that after irradiation the submicron and nanostructures (Figure 3c and 3d) have all disappeared and only a smooth sponge-like surface with protruding randomly oriented micron size pillars are reconstructed during the melt phase.
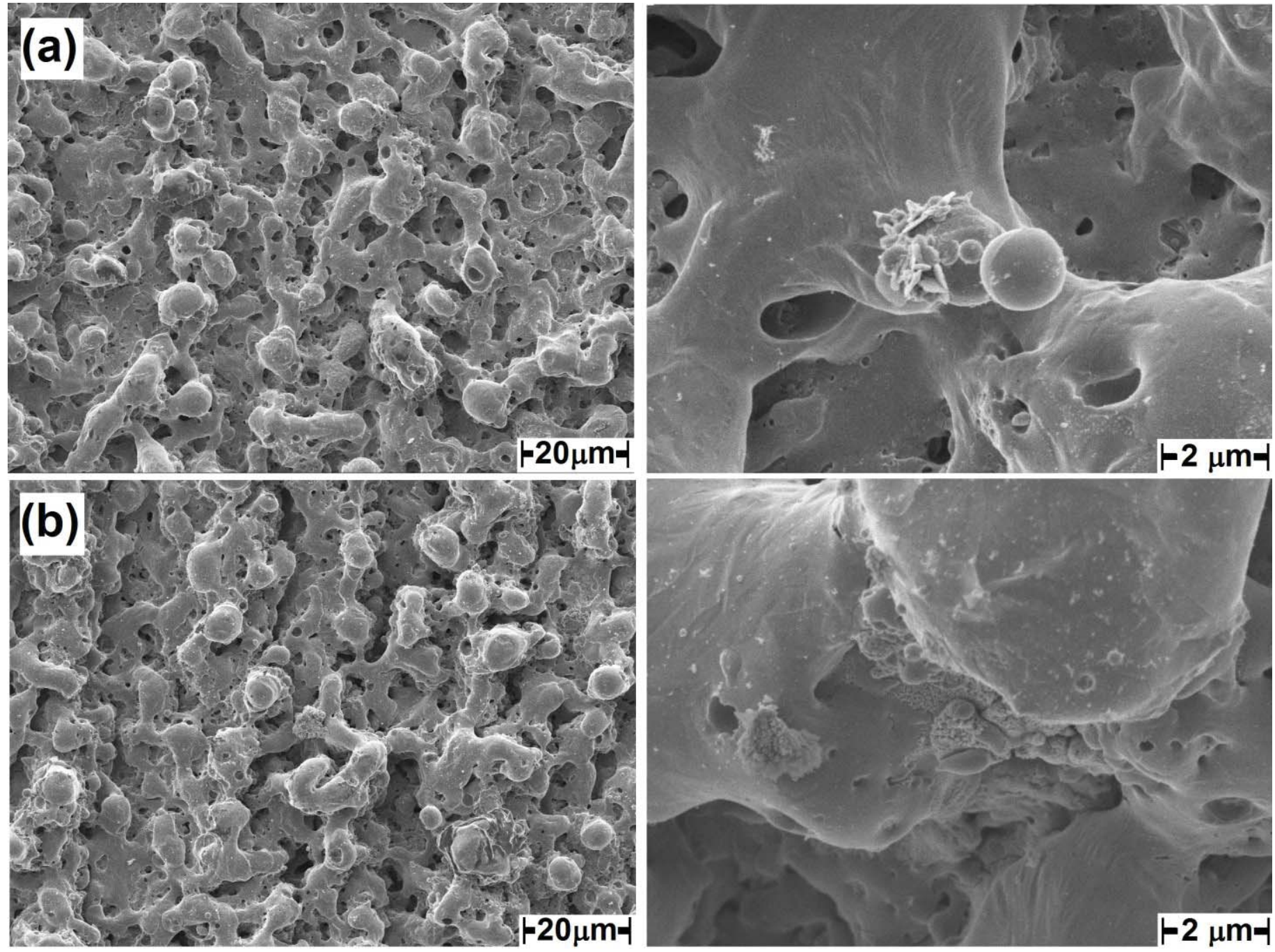

Figure 11: Low and high resolution planar SEM micrographs of the copper substrate irradiated with $\lambda=355 \mathrm{~nm}(\mathrm{Condition} 1)$ and post- irradiated with condition 5 and 6 successively. (a) Condition 1 at scan speed of $180 \mathrm{~mm} / \mathrm{s}$ (Sample 2*), (b) Condition 1 at scan speed of $120 \mathrm{~mm} / \mathrm{s}$ (Sample 3*).

The SEY as a function of primary electron energy of these surfaces are shown in Fig. 12. In both cases the trend of the SEY curve has reverted back to the universal SEY curve of untreated metal surfaces where the $\delta$ goes through a maximum following the sharper rise at primary electron energies $\mathrm{E}_{\mathrm{p}}<\mathrm{E}_{\max }$ and a slower fall at $E_{p}>E_{\max }$ as shown in Fig. 12. The value of $\delta$ over the full range primary electron energy is $10 \%$ lower for the higher scan speed $(120 \mathrm{~mm} / \mathrm{s})$ which had deeper grooves $(25 \mu \mathrm{m}$ as compared to $8 \mu \mathrm{m})$ after being irradiated with laser $\lambda=355 \mathrm{~nm}$. The $\delta_{\max }$ is 1.63 and 1.42 for 180 and $120 \mathrm{~mm} / \mathrm{s}$ scan speed, respectively. 


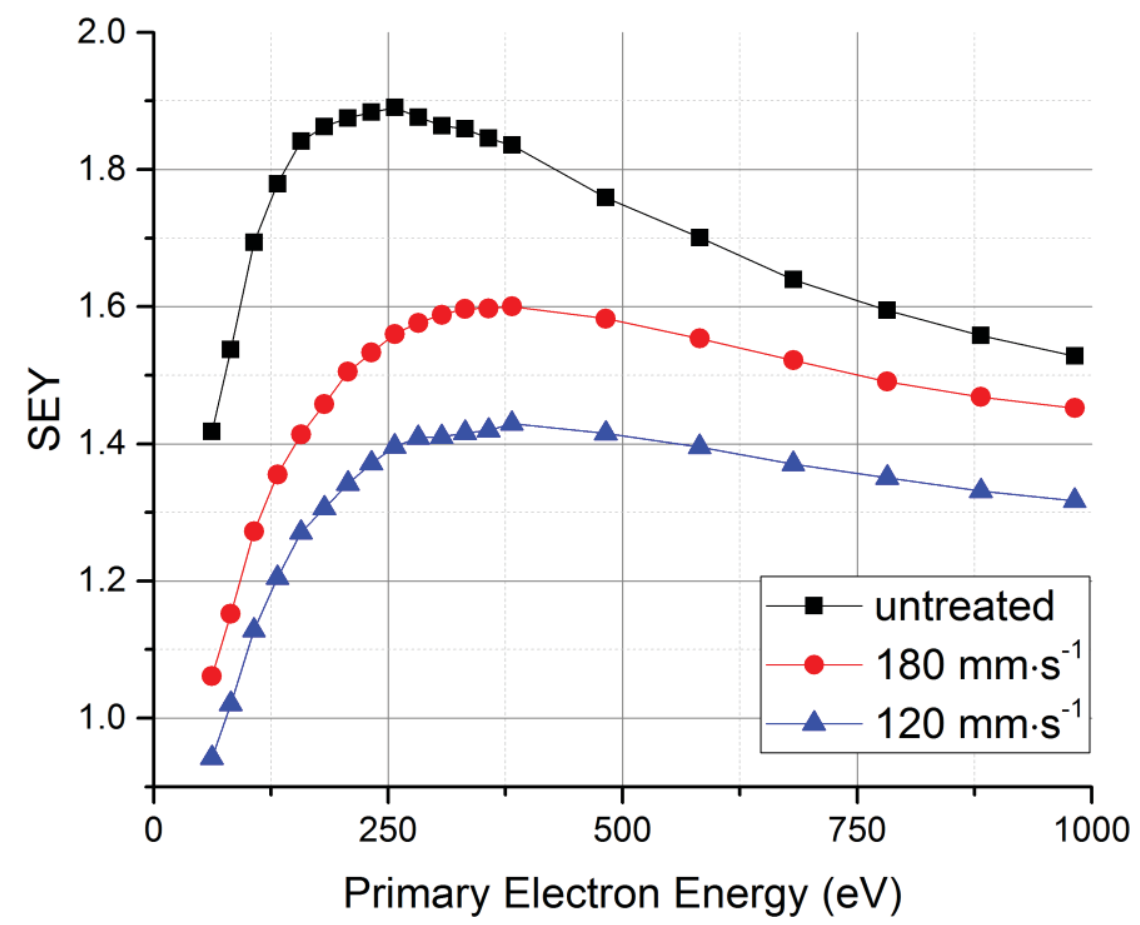

Figure 12: SEY as function of primary electron energy of Samples $2 *$ and $3 *$ twice laser treated (in comparison to untreated Sample 1.

Figure 13 represents the SEY of untreated copper plate (Sample 1), copper plate covered with thin layer of copper powder (Sample 11) and $0.5 \mathrm{~mm}$ of copper powder compacted on stainless steel sample plate (Sample 10). It can be seen that as the thickness of the layer powder increases the SEY curve shape changes to look more like the curves from the laser treated copper which suggests that similar processes are involved. The features in question are the flattening of the curve at energies between 400 and $1000 \mathrm{eV}$, it is shown that for some of the laser treated samples the SEY is increasing even at $1000 \mathrm{eV}$.

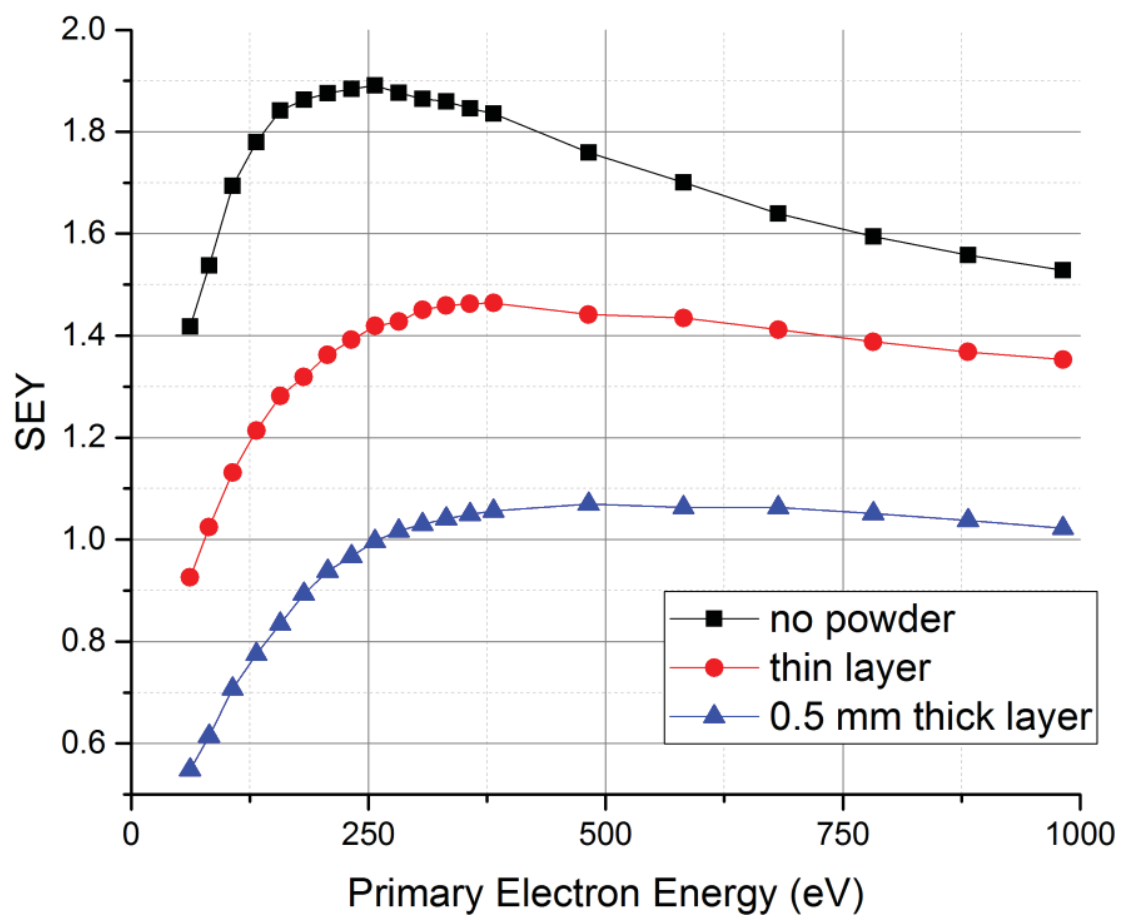

Figure 13: SEY as function of primary electron energy of copper substrate (Sample 1) and copper powder with different thickness (Samples 10 and 11). 


\section{DISCUSSION}

The principal application of this work is e-cloud and BIEM mitigation in a particle accelerator beam chamber. Thus, the most relevant results for this application correspond to primary electron energies comparable to those electrons impinging on accelerator beam chamber walls which are limited by two factors:

- Most of the photoelectrons are emitted at 10-20 eV and electrons with energies near the critical energy of synchrotron radiation.

- The secondary electrons can gain additional energy by acceleration in the beam potential, this energy is limited by the beam parameters.

The results of measurements reported in the literature show that energy of electrons impinging on the beam chamber is not greater than $600 \mathrm{eV}$ in the LHC [26] and SPS [27], and not greater than $500 \mathrm{eV}$ in RHIC [18]. Thus our study of SEY with primary incident electron energies up to $1 \mathrm{keV}$ provides sufficient information tom enable use of the results for e-cloud and BIEM modelling. Even though the SEY results presented above show that in all cases the SEY of LASE samples have a positive slope, i.e. all reported data are below or equal $E_{\max }$. However, all the LASE samples demonstrate a dramatic reduction in SEY in comparison to untreated surfaces and the majority of these samples have SEY $<1$ up to $1 \mathrm{keV}$.

The material parameters influencing the SEY are the penetration depth of the primary electron, the stopping power, the escape depth of the secondary electrons, the atomic number $\mathrm{Z}$ and, to a lesser extent, the work function [28]. It has been shown that the first crossover energy (where the SEY increases above 1) is strongly dependent on the surface properties whereas the energy at maximum yield is entirely controlled by bulk properties [29]. The escape depth for the true secondary is about $50 \mathrm{~nm}$ [30], so in order to decrease the SEY of an existing material using any of these parameters becomes a very difficult task and it has only been achieved by coating with a low SEY material [31]. The alternative method to lower the SEY is to trap the secondary emitted electron via the surface geometry such as high aspect ratio grooves [32] and surfaces covered by thin films [33].

The results presented in this study show that the SEY of copper plate as a function of primary electron energy can be reduced from 1.9 to below 1 by a Laser Ablation Surface Engineering (LASE) technique under a number of certain conditions. During the laser treatment the laser irradiation leads to material removal (e.g., ablation) and eventually to the formation of micro-, submicron and nano-structures. In our earlier work the main emphasis was put on microstructures (pyramids and grooves) [23], but the results presented above demonstrated the importance of submicron and nano-structures. As can be seen in the SEM images in this study, LASE has induced the grooves with tens of microns depth (microstuctures) and the groove walls are covered with submicron and nano-spheres or/and nano-wire structures.

The mechanism of laser ablation depends on material properties, laser properties, the environment and experimental parameters and is well described in the literature [34]. Two parameters were found to be 
crucial in forming these structures, the threshold value for ablation and the surface reflectivity. These two are closely linked as the threshold of ablation depends highly on the material reflectivity. Polished copper, which is highly reflective has a high threshold of ablation, however, once the surface ablation commences the pulse energy required is lowered as the losses through reflection are reduced because the structures in the material are formed, largely trapping the light rather than reflecting it. In our study, knowledge of the threshold fluence and the underlying ablation mechanism was found experimentally by producing a quick matrix by changing scan speed and the repetition rate. These produced visually black or dark surfaces. From laser parameters in Condition 1 it can be seen that, once the threshold fluence per pulse was fixed, the depth of the grooves has been increased by decreasing the scan speed. The deepening of the grooves is the result of successive irradiation of the same spot. During irradiation submicron and nano-size particulates are created due to the ablation. Successive irradiation may reduce the size of these particulates or increase their size by melting and recrystallization. The topography observed in Figs. 3 and 7 is the consequence of this mechanism. The reduction of SEY is induced by submicron structures and nano-spheres superimposed on grooves which have depth ranging from 5 to $100 \mu \mathrm{m}$. This reduction is more enhanced at primary electron energy below $400 \mathrm{eV}$. The SEY results of samples being irradiated under Condition 1 shows that the optimum groove depth ranges from 25 to $60 \mu \mathrm{m}$. As the groove depth decreases, the effectiveness of the reduction in SEY slowly diminishes for primary electron energy above $500 \mathrm{eV}$, this is evident in the case of sample being irradiated at a scan speed of $180 \mathrm{~mm} / \mathrm{s}$ where the topography of the irradiated surface consists of submicron structures and nano-spheres superimposed on $8 \mu \mathrm{m}$ deep grooves. This may not be the ideal SEY behaviour as a function of primary electron energy but it is quite acceptable where there is a need for compromise between an acceptable value of SEY and the surface impedance which increases with the groove depth [25].

Laser ablation under Condition 4 (Sample 9) also produced very similar results to ones obtained in Condition 1 (Sample 5, scan speed of $60 \mathrm{~mm} / \mathrm{s}$ ) both in terms of LASE induce surface topography (see Fig. 7) and SEY trend as a function of primary electron energy (see Fig. 8). The importance of this result is that it demonstrates that these surfaces can be achieved with different laser wavelengths; this can be very important in scaling up of this technology.

Laser ablation under Conditions 2 and 3 resulted in submicron coral-like features covered with nanowires superimposed on shallow grooves. The SEY of this type of topography has some similarity with the SEY trend of LASE induced topography of $180 \mathrm{~mm} / \mathrm{s}$ scan speed in Condition 1. The SEY is below 1 for primary electron energy below $200 \mathrm{eV}$ and then rises quite sharply above $\mathrm{E}_{\mathrm{p}}=200 \mathrm{eV}$, however the SEY is still lower than for reference Sample 1.

Samples 2 and 3, which have surfaces covered by submicron structures and nano-spheres produced by laser ablation under parameters set in Condition 1 and demonstrate $\mathrm{SEY}<1$, were further irradiated using a $\lambda$ $=1064 \mathrm{~nm}$ laser at below ablation threshold. After this treatment the SEY has increased for both samples. The main difference between Samples 2 and 3 (before the second laser treatment shown in Fig. 2 (a) and (b)) and Samples 2* and 3* (after the second laser treatment shown in Fig. 11 (a) and (b)) is the disappearance of 
the submicron and nano-spheres, while the grooves are still present. Therefore, it has been shown that the removal of submicron and nano-spheres structure leads to SEY increase.

The Samples 7 and 8 demonstrate another type of nanostructure: nano-size wire/filament/fibre like structure. This type of nanostructure is less efficient for SEY reduction than the nano-spheres in Samples 26. Thus the results from Samples 7, 8, 2* and $3 *$ demonstrate the role of nano-spheres in the reduction of SEY.

The importance of the nanospheres was further demonstrated when the surfaces of a copper and stainless steel sample plates (Samples 10 and 11) were covered with different thickness of copper powder. The SEY trend showed a very good resemblance to the results obtained for all samples irradiated with laser and induced nano-sphere topography. Similar results were reported by other investigators [35] where they covered the surface of metal sample with soot for different thicknesses.

Another important point that needs to be taken into consideration is that LASE was carried out in air which led to creation of copper oxide. The surface chemistry of the post laser irradiation was examined using XPS and showed the presence of the $\mathrm{Cu}^{2+}$ broad peak (shake up satellite) at binding energy of $943 \mathrm{eV}$. Also, in all cases no carbon peak was observed. It is well known that the oxides of metals produce high SEY due to the increase of the escape depth of the generated electron because of reduction in number electronelectron interactions [36,37]. However, even in this condition with the surface in an oxide state the SEY stays below 1 due the multiple trapping sites of the grooves and the possible reduced density of the submicron structure and nano-spheres which can have sizes very similar to the escape depth (50 nm) and the shadowing effect of adjacent submicron and nanostructures.

The results obtained in this study overwhelmingly demonstrate that LASE is a very versatile technology for the reduction of the SEY of copper surfaces and it is foreseen to be very easily scalable. In application to particle accelerators the technology for e-cloud mitigation should include not only the SEY reduction but also should keep surface impedance as close as possible to the untreated surface. It was shown previously [25] that the surface impedance increases significantly with depth of grooves, therefore in the LASE optimisation for low SEY surfaces the depth of grooves should be reduced and reduction of SEY would be obtained with submicron and nano-sphere structures.

Although LASE can reduce SEY quite effectively, it creates a lot of particles during ablation, the majority of which are welded into the surface in the following cycle. Great care must be taken to either blow or extract, by vacuum cleaner, the excess particulate during or after processing. Another possible way of mitigating loose particles could be a post laser irradiation with pulse fluence below the ablation threshold to weld any remaining particles.

In our first paper on the discovery of LASE surfaces for e-cloud mitigation we have shown the importance of microstructure grooves and pyramids [23]. In this work we have demonstrated that submicron and nanostructures also play an important and significant role in suppression of SEY and that various lasers can be used to produce these submicron and nano-structures. However, this study opens the door to many question such the SEY for primary electrons with energy below $60 \mathrm{eV}$ [38], the energy distribution of secondary 
electrons for all ranges of primary electron energies and the effect of surface composition. Therefore a lot of work should be done to answer these questions.

It was shown above that lasers with various parameters can produce the desired surfaces with submicronand nano-structures. Only two nanosecond lasers were used in this study, however is know from the literature that LASE can be also produced with fs lasers $[39,40]$. The SEY study of such surfaces remains a subject of future publications.

\section{CONCLUSION}

Laser ablation surface engineering is a promising method of reducing SEY below 1 with the aim of eradicating e-cloud and electron multipacting by the formation of organised surface micro- and nanostructures. Laser processing parameters can be easily adjusted resulting in a great variety of possible structures.

It has been demonstrated that not only microstructure (grooves) but the nano-structures as well are playing a role in reducing SEY. It was found that the most efficient nano-structures for SEY reduction is submicron and nano-sphere structures, which allows one to keep $\mathrm{SEY}<1$ even at much reduced groove depth.

It was also demonstrated that these surfaces can be produced using various lasers with different wavelength, such as $\lambda=355 \mathrm{~nm}$ and $\lambda=1064 \mathrm{~nm}$, with optimised laser parameters such as pulse length, repetition rate, power, fluence, beam size, scan speed and distance between scanned lines.

\section{ACKNOWLEGMENTS}

This work was conducted under the aegis of the Science \& Technology Facility Council (STFC). S. Wang would like to acknowledge the support provided by ASTeC and Loughborough University, with a great appreciation of time and support from Prof. E. Seddon. T. Sian would also like to acknowledge the support provided by European Union's EuroCirCol collaboration H2020 Framework Programme under grant agreement no. 654305 .

\section{REFERENCES:}

[1] G. Rumolo, G. Arduini, V. Baglin, H. Bartosik, N. Biancacci, et al. Electron cloud observations in LHC. Proc. of IPAC2011, San Sebastián, Spain (2011) p. 2862.

[2] J. A. Crittenden, J. V. Conway, G. Dugan, M.A. Palmer, D.L. Rubin, K. Harkay, L. Boon, M.A. Furman, S. Guiducci, M.T.F. Pivi and L. Wang. Investigation into electron cloud effects in the ILC damping ring design. Proc. of IPAC-2012, New Orleans, Louisiana, USA, p. 1963 (2012).

[3] F. Zimmermann. Review of single bunch instabilities driven by an electron cloud. Phys. Rev. ST Accel. Beams 7, 124801 (2004).

[4] S. Kato, M. Nishiwaki. e-Cloud Activity of DLC and TiN Coated Chambers at KEKB Positron Ring. Proc. of Ecloud'10, Ithaca, New York, USA (2010), p. 37. 
[5] D. Alesini, T. Demma, A. Drago, A. Gallo, S. Guiducci, C. Milardi, P. Raimondi, M. Zobov, S. De Santis, T. Demma, P. Raimondi. Experimental measurements of e-cloud mitigation using clearing electrodes in the DAФNE collider. Proc. of IPAC-2012, New Orleans, Louisiana, USA, p.1107 (2012).

[6] W. Fischer, U. Iriso. Bunch patterns and pressure rise in RHIC. Proc. of EPAC'04, Lucerne, Switzerland, July 2004, p. 914.

[7] A. Kulikov, A. Fisher, S. Heifets, J. Seeman, M. Sullivan, U. Wienands, W. Kozanecki. The electron cloud instability at PEP-II. Proc. PAC'01, Chicago, Illinois, USA, p.1903 (2001).

[8] Handbook of accelerator physics and engineering. Ed. M. Tigner, A. Chao, World Scientific,1998, p. 131.

[9] R. Cimino and T. Demma. Electron Cloud in Accelerators. Int. J. Modern Phys. A 29 (2014), 1430023.

[10] G. Budker, G. Dimov, V. Dudnikov. Experiments on production of intense proton beam by charge exchange injection method. In Proceedings of the International Symposium on Electron and Positron Storage Rings, Saclay, France, 1966, Article no. VIII-6-1 (1966).

[11] G. Budker, G. Dimov, and V. Dudnikov. Experimental investigation of the intense proton beam accumulation in storage ring by charge-exchange injection method, Soviet Atomic Energy, 22, 384 (1967).

[12] J.A. Crittenden, J.V. Conway, G. Dugan, M.A. Palmer, D.L. Rubin, K. Harkay, L. Boon, M.A. Furman, S. Guiducci, M.T.F. Pivi and L. Wang, Proc. of IPAC-2012, New Orleans, Louisianna, USA, p. 1963

[13] O. Brüning and F. Zimmermann. Parameter Space for the LHC Luminosity Upgrade, Proc. of IPAC'12 New Orleans, p. 127, (2012).

[14] K. Ohmi, L. Mether, D. Schulte, F. Zimmermann. Study of electron cloud instabilities in FCC-hh. Proc. of IPAC-2015, Richmond, VA, USA, p. 2007 (2015).

[15] H. Fukuma. Electron Cloud Observations and Predictions at KEKB, PEP-II and SuperB Factories. Proc. Of Ecloud'12, 5-9 Jun 2012, La Biodola, Isola d'Elba, Italy, p. 27 (2012).

[16] G. Stupakov and M. Pivi. Suppression of the effective SEY for a grooved metal surface, Proc. of ECLOUD’04, Napa, California, 19-23 April 2004, p.139 (2004).

[17] P. He, H.C. Hseuh, M. Mapes, R. Todd and D. Weiss. Development of titanium nitride coating for SNS ring vacuum chambers. Proc. PAC01, p.2159 (2001).

[18] W W. Fischer, M. Blaskiewicz, J. M. Brennan, H. Huang, H.-C. Hseuh, V. Ptitsyn, T. Roser, P. Thieberger, D. Trbojevic, J. Wei, S. Y. Zhang, and U. Iriso. Electron cloud observations and cures in the Relativistic Heavy Ion Collider. Phys. Rev. ST Accel. Beams 11, 041002 (2008).

[19] C. Yin Vallgren, G Arduini, J.Bauche, S. Calatroni, P. Chiggiato, K. Cornelis, P. Costa Pinto, E. Metral, G. Rumolo, E. Shaposhnikova, M. Taborelli, G. Vandoni. Amorphus carbon coatings for mitigation of electron cloud in the CERN SPS. Proc. IPAC'10, Kyoto, Japan, paper TUPD048, p. 2033 (2010).

[20] S. Wang. PhD Thesis. Loughborough University, UK, July 2016.

[21] I. Montero, L. Aguilera, M.E. Dávila, et al. Novel types of anti-ecloud surfaces. In proc. of ECLOUD12 workshop, ELBA, Italy, 2012, p. 153.

[22] M. Ye, Y.N. He, S. G. Hu, R. Wang, T.C. Hu, J. Yang and W.Z. Cui. Suppression of Secondary Electron Yield by Micro-Porous Array Structure. J. Appl. Phys. 113, 074904 (2013).

[23] R. Valizadeh, O.B. Malyshev, S. Wang, et al. Low secondary electron yield engineered surface for electron cloud mitigation. App. Phys. Lett. 105, 231605 (2014).

[24] R. Valizadeh, O. Malyshev. Apparatus and methods relating to reduced photoelectron yield and/or secondary electron yield. Patent publication number WO2015189645 A1. 17th Dec 2015.

[25] R. Valizadeh, O.B. Malyshev, S. Wang, T. Sian, L. Gurran, P. Goudket, M.D. Cropper, N. Sykes. Low secondary electron yield of laser treated surfaces of copper, aluminium and stainless steel. In Proc. of IPAC'16, 8-13 May 2016, Busan, Korea (2016), p. 1089.

[26] J.M. Jimenez, B. Henrist, J-M. Laurent, K. Weiss. Electron cloud heat load estimations for the LHC using strip and retarding field detectors. LHC Project Report 677. CERN, Geneva, 2003.

[27] J-M. Laurent, H. Song. electron cloud energy and power measurements in SPS. Vacuum Technical Note 04-02. CERN, Geneva, 2004.

[28] Y. Lin and D.C. Joy. A new examination of secondary electron yield data. Surface and Interface Anal. 37, 895 (2005).

[29] G.F. Dionne. Origin of secondary-electron-emission yield-curve parameters. J. Appl. Phys. 46, 3347 (1975). 
[30] K. Kanaya and S. Okayama. Penetration and energy loss theory of electrons in solid targets. J. Phys.D: Appl. Phys. 5, p. 43 (1972).

[31] C. Yin Vallgren, G. Arduini, J. Bauche, S. Calatroni, P. Chiggiato, K. Cornelis, P. Costa Pinto, B. Henrist, E. Metral, H. Neupert, G. Rumolo, E. Shaposhnikova, and M. Taborelli. Amorphous carbon coatings for the mitigation of electron cloud in the CERN Super Proton Synchrotron. Phys. Rev. ST Accel. Beams, 14, 071001 (2011).

[32] Y. Suetsugu, H. Fukama, K.Shibata, M. Pivi, L. Wang. Experimental studies on grooved surfaces to suppress secondary electron emission. Proc. IPAC10, Kyoto, Japan, TUPD043, p. 2021 (2010).

[33] S. Wang, O.B. Malyshev, R. Valizadeh, E.A. Seddon, M.D. Cropper. The secondary electron yield from transition metals. Proc. of IPAC2014, Dresden, Germany, 2014, p. 2403 (2014).

[34] K.-H. Leitz, B. Redlingshöfer, Y. Reg, A. Otto, M. Schmidt. Metal ablation with short and ultrashort laser pulses. Physics Procedia 12B, pp. 230-238 (2011).

[35] H. Bruining, Physic and Application of Secondary Electron Emission. Pergamon, London, 1964.

[36] A. Shih, J. Yater, C. Hor, R. Abrous. Secondary electron emission studies. Appl. Surf. Sci. 111, p. 251 (1997).

[37] A.J. Dakker. Solid State physics, Advantages in Research. and Applications, ed. by F. Seitz and Turnbull, Academic Press New York, p. 251 (1958).

[38] R. Cimino, L.A. Gonzalez, R. Larciprete, A. Di Gaspare, G. Iadarola, G. Rumolo. Detailed investigation of the low energy secondary electron yield of technical $\mathrm{Cu}$ and its relevance for the LHC. Phys. Rev. Special Topics - Accel and Beams 18, p. 5 (2015).

[39] K.M. Tanvir Ahmmed, C. Grambow and A.-M. Kietzig. Fabrication of Micro/Nano Structures on Metals by Femtosecond Laser Micromachining. Micromachines 5, pp. 1219-1253 (2014).

[40] J. Byskov-Nielsen, J.-M. Savolainen, M. S. Christensen, P. Balling. Ultra-short pulse laser ablation of metals: threshold fluence, incubation coefficient and ablation rates. Appl. Phys. A 101, pp. 97-101(2010). 